\title{
Detailed study on the effect of different ignition enhancers in the binary blends of diesel/biodiesel as a possible substitute for unaltered compression ignition engine
}

\author{
Yuvarajan Devarajan $^{1} \cdot$ Dineshbabu Munuswamy $^{2} \cdot$ Beemkumar Nagappan $^{3} \cdot$ S. Ganesan ${ }^{4}$
}

Received: 30 September 2019 / Published online: 30 May 2020

(c) The Author(s) 2020

\begin{abstract}
This study examines the impact of the oxygenated additives namely DTBP (Di-Tetra-Butyl-Phenol) and 1-Pentadecanol (1-DEC) on emissions, combustion and performance patterns of Karanja biodiesel/diesel blends. Two additives were selected as ignition improver owing to their improved physicochemical properties. The additives were mixed at $10 \%$ volume with the equal blends of diesel and biodiesel. Experimental results revealed that by adding additives and biodiesel to diesel found no phase separation. HRR and peak pressure were highest for diesel and least for KBD/D blends. However, blending the additives enhanced its HRR and peak pressure. Addition of additives lowered the harmful emissions significantly with a slight increase in $\mathrm{NO}$ emissions to the $\mathrm{KBD} / \mathrm{D}$ blends. In addition, a noteworthy increase in performance aspects was observed for $\mathrm{KBD} / \mathrm{D}$ blends by adding DTBP and 1-Pentadecanol.
\end{abstract}

Keywords Engine $\cdot$ Additive $\cdot$ Alcohol $\cdot$ Biodiesel $\cdot$ Diesel $\cdot$ Karanja

$\begin{array}{ll}\text { Abbreviations } & \\ \text { 1-DEC } & \text { 1-Pentadecanol } \\ \text { DTBP } & \text { Di-Tetra-Butyl-Phenol } \\ \text { D } & \text { Diesel } \\ \text { KBD } & \text { Karanja biodiesel } \\ \text { CV } & \text { Calorific value } \\ \text { KBD/D } & 50 \% \text { Karanja biodiesel and 50\% Diesel } \\ \text { KBD/D/DTBP } & 45 \% \mathrm{BD}, 45 \% \mathrm{D} \text { and 10\% DTBP by } \\ & \text { volume } \\ \text { KBD/D/1-DEC } & 45 \% \mathrm{BD}, 45 \% \mathrm{D} \text { and 10\% 1-Pentade- } \\ & \text { canol by volume }\end{array}$

Edited by Xiu-Qiu Peng

Yuvarajan Devarajan

dyuvarajan2@gmail.com

1 Department of Mechanical Engineering, Madanapalle Institute of Technology \& Science, Madanapalle 517325, India

2 Department of Mechanical Engineering, Panimalar Engineering College, Chennai, India

3 Department of Mechanical Engineering, Jain University, School of Engineering and Technology, Banglore, India

4 Department of Mechanical Engineering, Sathyabama Institute of Science and Technology, Chennai, India

\section{Introduction}

Economic growth and social development depend on energy generation and utilization. The power produced by renewable source than conventional technologies is vital on the socioeconomic effect on the local economy. To lower the dependency on diesel fuel and conventional gasoline from crude oil, liquid biofuels are extensively investigated as a potential alternate source. Environmental, economic and social factors with respect to biodiesel are overviewed, and the problem linked with the demand for future fuels encourage the energy experts to focus on biofuels. Alcohols, biogas and biodiesel are encouraging transportation fuels. Among which biodiesel (BD) is widely followed owing to its comparable properties with fossil fuels. Many studies were conducted on the biodiesel as a neat or partial replacement to diesel. Appavu (2018) examined the emissions and performance patterns of CI engine fuelled with diesel and palm-biodiesel. He found that palm-biodiesel lowered the emissions and performance at all loads. Radhakrishnan et al. (2018) studied the emissions characteristics of diesel engine propelled with diesel and the blends of palm-biodiesel and diesel. He observed a drastic reduction in tailpipe emission by blending biodiesel to diesel at all testing conditions. Devarajan et al. (2019a) investigated the performance and exhaust emissions of a diesel engine using Punnai biodiesel 
with diesel blends at different conditions. They found that Punnai biodiesel/diesel blends lowered carbon monoxide, hydrocarbon and smoke opacity than diesel at all loads. Siva et al. (2018) examined the emissions and performance patterns of CI engine fuelled with diesel and orange peel biodiesel. He found that orange peel biodiesel lowered the emissions as well as the performance patterns of the engine at different speeds. Devarajan (2018) investigated the performance and exhaust emissions of a diesel engine using mustard biodiesel with diesel blends at different conditions. They found that mustard biodiesel/diesel blends lowered carbon monoxide, hydrocarbon and smoke opacity than diesel at all loads with a notable reduction in SFC and BTE.

Nevertheless, high NOx emissions, expensive feedstock, fuel stability and higher viscosity have limited its active usage. Carbon precipitates, cold-start complexity, higher BSFC, higher pour point, lower BTE are the additional limitation of BD. The usage of BD shall be improved by blending with additives with improved physicochemical properties. Higher alcohols (HA) and ignition enhancer (IE) shall be promising additives to improve the ignition properties of BD. HA and IE are loaded with improved properties such as higher cetane number, improved miscibility and higher calorific value. HA and IE are produced by the fermentation process of biomass and biowaste. The effective blending of $\mathrm{HA}$ and IE with $\mathrm{BD} /$ diesel blends results in a higher power and lower emissions than neat BD. Among available additives, 1-Pentadecanol and DTBP are found to be appropriate candidate owing to their improved chemical and physical properties. Blending 1-Pentadecanol and DTBP to BD/D blends will reflect inferior emissions, enhanced combustion and improved performance. Cetane number, calorific value, lower pressures (vapor), flash point are the other positive properties of 1-Pentadecanol and DTBP. 1-Pentadecanol and DTBP provide the ignition quality and enhanced phase stability than other additives. The surplus oxygen available in DTBP and 1-Pentadecanol promotes the oxidation process and limits the emissions.

Many works reported the positive characteristics of other HA (hexanol, butanol and pentanol) and IE (DEE, DME and DMC) on diesel/biodiesel blends. Devarajan et al. (2019b) investigated the appropriateness of octanol in Rice bran BD at $10 \%-20 \%$ in steps of $10 \%$ volume for CI engine. BD was varied from $100 \%$ to $80 \%$, and the magnitude of octanol was varied consequently. Results found lower BSFC and higher BTE by adding octanol on $20 \%$ volume basis. Octanol blending to $\mathrm{BD}$ enhanced heat release rate and cylinder pressure. In addition, the $10 \%$ octanol BD results in lowered NO (3.7\%) and CO (6.8\%) emission. Devarajan et al. (2019b) employed $10 \%$ and $20 \%$ of butanol with Punnai BD in constant speed engine. Investigation revealed that the postblending of butanol to Punnai BD lowered all the emissions associated with BD. Joy et al. (2019) investigated the usage of DME as IE in cashew nutshell BD at $10 \%-20 \%$ in steps of $10 \%$ volume in constant speed diesel engine. $100 \%, 90 \%$ and $80 \%$ volume of cashew nut shell BD was mixed with $10 \%$ and $20 \%$ of DME at room conditions. Upon inclusion of DME to cashew nutshell BD at $20 \%$ volume, $\mathrm{HC}(4.2 \%), \mathrm{CO}$ (3.4\%), smoke (8.4\%) and NO (8.8\%) emissions were lower than neat BD. In another investigation, Devarajan (2018) employed $10 \%$ and $20 \%$ of DMC (dimethyl carbonate) with almond $\mathrm{BD}$ in constant speed engine. Investigation revealed that the post-blending of DMC to almond BD enhanced the BTE and lowered BSFC and all the emissions of BD.

Key findings from the above studies proved that the IE and HA are promising means to lower the limitations of $\mathrm{BD}$ and enhance its usage as fuel in CI engine. Besides, the energy utilization from non-edible feedstock (Karanja Seeds) attracts attention among researchers. It is obtained by pongam tree seeds. Karanja seeds are literally waste products with considerable energy content in it. The energy (calorific value) from Karanja Seeds makes it a potential source of BD. The higher density and viscosity limits its usage as blended fuel. However, the ignition properties of Karanja biodiesel (KBD) shall be considerably improved by mixing it with IE (DTBP) and HA (1-Pentadecanol). The enhancement in physicochemical properties of KBD upon inclusion of additives will reduce the limitations and make it as a viable partial alternate to diesel. The chosen additives were mixed at $10 \%$ volume with the equal blends of diesel and biodiesel to its combustion, performance and emissions pattern of the diesel engine. The obtained results of modified fuels are compared with diesel and diesel/Karanja biodiesel blends.

\section{Materials and methods}

\subsection{Fuel preparation}

FFA (free fatty acid) is a major parameter for biodiesel. Around $8 \%$ of FFA was found from raw Karanja oil (KO). FFA content of raw oil is converted into methyl form by three-step transesterification technique. The initial reduction in FFA is carried out by acid-catalyst transesterification. It is then followed by alkali-catalyst transesterification and purification thereafter. Initially, the raw $\mathrm{KO}$ and a mixture of methanol and sulfuric acid are measured on the molar ratio of $16: 1$ and heat for $60 \mathrm{~min}$ to $65^{\circ} \mathrm{C}$. The obtained mixture is reheated by adding methanol at a molar ratio of $5: 1$. Subsequently, to obtain the methyl ester, $1.1 \%$ weight of catalyst $(\mathrm{KOH})$ is included in the mixture and heated for $30 \mathrm{~min}$ to $60^{\circ} \mathrm{C}$. Later, methanol in the mixture is removed and purified by heating the mixture to its boiling point. After transesterification, $94 \%$ of yield was obtained from raw KO. 


\subsection{Blends preparation}

Four different fuels were investigated in the diesel engine during the experimentation. Biodiesel (KBD) and diesel each were blended exactly at $50 \%$ by volume and termed as KBD/D. The chosen additives were mixed at $10 \%$ volume with the equal blends of diesel and biodiesel. For instance, DTBP at $10 \%$ volume is mixed with the blend containing $45 \%$ of diesel and $45 \%$ of biodiesel and termed as "KBD/D/ DTBP." Further, 1-Pentadecanol at 10\% volume is mixed with the blend containing $45 \%$ of diesel and $45 \%$ of biodiesel and termed as "KBD/D/1-DEC" by splash blending technique. Wider acceptance and the lower cost was the major cause of choosing splash blending. Upon investigation, all the samples were found stable and well mixed. The density of test fuels was calculated by employing digital density meter in line with ASTM D1298. Kinematic viscosity replicates the resistant to flow by any liquid. The viscosity of test fuels was computed with respect to ASTM D445 testing standards and the attained value as well with the standard.
The heating value of tested fuels was calculated by bomb calorimeter based on ASTM D240 testing procedure. Cetane number of test fuels is determined by API gravity and midboiling point of the sample. According to ASTM D 976 testing procedure, the obtained cetane number of test fuels was observed in the agreed standards. Pensky-Martens closed cup equipment in line with ASTM D93 testing standard was employed to compute the flash point of test fuels. Significant properties of test fuels are presented in Table 1.

\subsection{Experimental setup and procedure}

This work used a single-cylinder, four-stroke engine coupled with eddy current model dynamometer (Fig. 1, Table 2). The emissions, for instance, $\mathrm{CO}, \mathrm{NO}_{\mathrm{X}}$, and $\mathrm{HC}$ were calculated by AVL emissions analyzer. AVL opacimeter is used to compute smoke. AVL INDMICRA were used to examine the output data from transducer and encoder. "Engine-soft" software package was used to examine BSFC and BTE. It is essential to analyze the error value or the uncertainty to

Table 1 Tested fuel physical properties

\begin{tabular}{lllll}
\hline Property & Diesel & KBD/D & KBD/D/1-DEC & KBD/D/DTBP \\
\hline Density, $\mathrm{kg} / \mathrm{m}^{3}$ & 750 & 780 & 770 & 750 \\
Kinematic viscosity @ $40{ }^{\circ} \mathrm{C}, \mathrm{cSt}$ & 3.1 & 3.4 & 3.2 & 3.1 \\
Calorific value, $\mathrm{KJ} / \mathrm{kg}$ & 42,500 & 41,600 & 41,750 & 41,900 \\
Cetane number & 47 & 54 & 57 & 59 \\
Flash point, ${ }^{\circ} \mathrm{C}$ & 75 & 88 & 92 & 95 \\
\hline
\end{tabular}

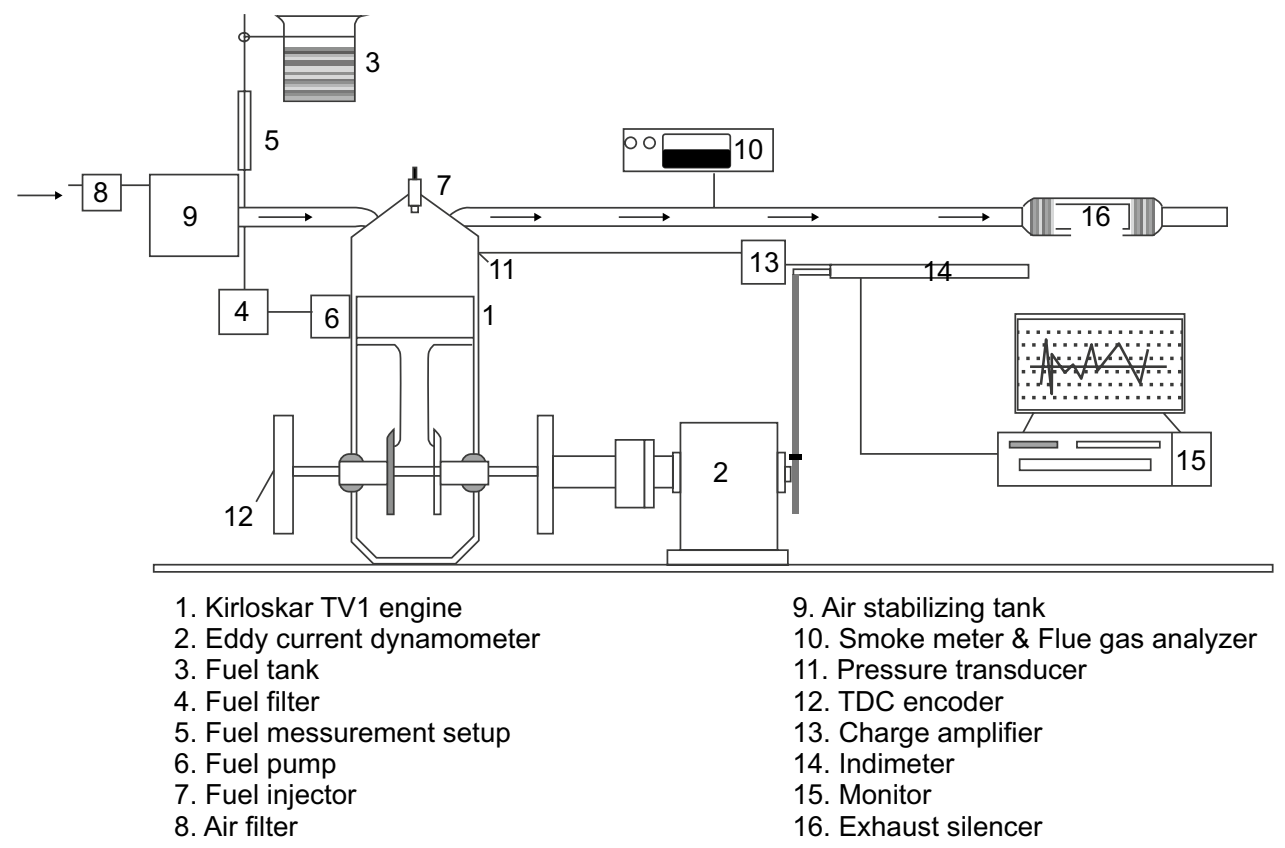

Fig. 1 Layout of the experimental setup 
Table 2 Engine specifications

\begin{tabular}{ll}
\hline Make and model & Kirloskar, TV1 \\
\hline Number of cylinders & One \\
Stroke & Four \\
Bore & $87.5 \mathrm{~mm}$ \\
Stroke length & $110 \mathrm{~mm}$ \\
Swept volume & $661 \mathrm{cc}$ \\
Compression ratio & 17.5 \\
Rated output & $5.5 \mathrm{~kW}$ \\
Rated speed & $2400 \mathrm{rpm}$ \\
Cooling system & Water-cooled \\
Injection timing, CA bTDC & $17^{\circ}$ \\
\hline
\end{tabular}

acquire the correctness of obtained values. Uncertainty is governed by the incidental or direct effect of various factors such as data recording, environment circumstances, operating condition, range and tuning of the employed apparatus. Uncertainty analysis predicts the appropriateness of the value obtained during the experimentation. This study followed the backward propagation inaccuracy study proposed by J. P. Holman. As per the analysis, the overall uncertainty on engine emission and performance parameters were found to be $\pm 2.12 \%$. The complete trial was conducted in a diesel engine by varying the load at a constant speed of $1500 \mathrm{rpm}$, while the fuel injection was retained as $23^{\circ}$ before TDC. Primarily, the diesel engine was allowed to run with neat diesel for $30 \mathrm{~min}$ to attain steady-state subsequently; allimportant ignition factors were documented. Correspondingly, the ignition factors were recorded for other test fuels such as KBD/D, KBD/D/1-DEC and KBD/D/DTBP.

\section{Results and discussion}

\subsection{In-cylinder pressure variation}

Peak pressure for tested fuels namely, KBD/D, Diesel, KBD/ $\mathrm{D} / 1$-DEC, KBD/D/DTBP is shown in Fig. 2. Diesel generates 64.8 bar, whereas KBD/D, KBD/D/1-DEC and KBD/D/ DTBP produce 60.5 bar, 62.8 and 63.6 bar, respectively. Peak pressure of DTBP/1-Pentadecanol/KBD/diesel blends is lower than diesel at full load. This lower peak pressure is due to lower heating content and inferior auto-ignition characteristics of modified fuel than diesel (Ganesan 2019; Kavitha et al. 2019). Peak pressure of KBD/D blends is least among all fuels. It shall be correlated to its inferior physicochemical properties than other fuels. Peak pressure of DTBP/1-DEC/KBD/D blends is higher than KBD/D blends. Higher heating value, lower viscosity, higher $\mathrm{O}_{2}$ availability leads to uniform burning and higher pressure (Mahalingam

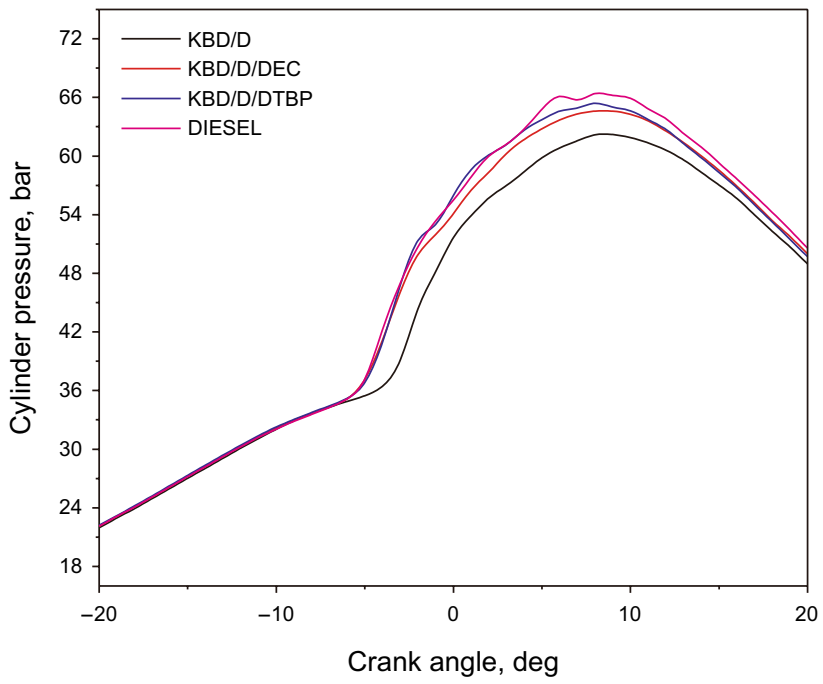

Fig. 2 Variation in pressure with crank angle

2018). The peak pressure of KBD/D/DTBP blends is 0.8 bar higher than KBD/D/1-DEC blends. Self-ignitability of $\mathrm{KBD} / \mathrm{D} / \mathrm{DTBP}$ blends is higher than KBD/D/1-DEC blends owing to its higher cetane number. Further, KBD/D/DTBP blends owing to higher cetane number ignite early and uniformly and burn completely and end up with higher pressure. Devarajan et al. (2020) attempted butanol as an additive to neat $\mathrm{BD}$ and achieved higher peak pressure than BD.

\subsection{Heat release rate}

HRR for KBD/D, diesel, KBD/D/1-DEC, KBD/D/DTBP is shown in Fig. 3. Diesel generates 69.8 J/CA, whereas

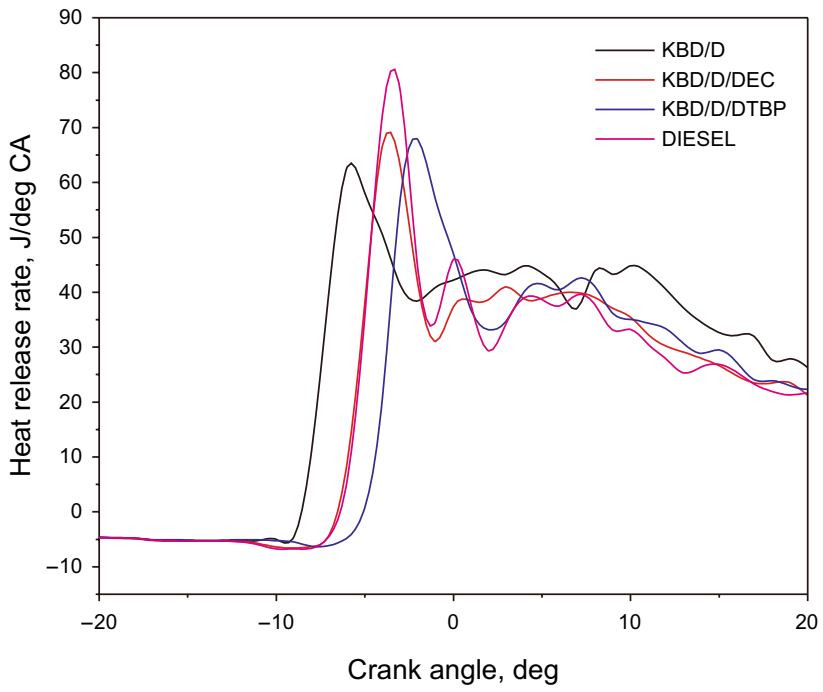

Fig. 3 Variation in ss angle 
$\mathrm{KBD} / \mathrm{D}, \mathrm{KBD} / \mathrm{D} / 1-\mathrm{DEC}$ and KBD/D/DTBP produce $62.9 \mathrm{~J} / \mathrm{CA}, 64.8 \mathrm{~J} / \mathrm{CA}$ and $66.9 \mathrm{~J} / \mathrm{CA}$, respectively. HRR for $\mathrm{DTBP} / 1$-Pentadecanol/KBD/diesel blends is lower than diesel. Lower CV and superior flash point lead to lower HRR (Jayabal et al. 2019). HRR for KBD/D blends is least among fuels. This is correlated with its lesser physicochemical properties. KBD/D/DTBP and KBD/D/1-DEC blends produce higher HRR than KBD/D blends. Significant increase in HRR is correlated with less density, less viscosity, $\mathrm{O}_{2}$-rich combustion of modified fuels (KBD/D/DTBP and KBD/ $\mathrm{D} / 1$-DEC). Further, the HRR for KBD/D/DTBP blends is $2.1 \mathrm{~J} / \mathrm{CA}$ higher than KBD/D/1-DEC. This is due to better atomization process, improved mixing and complete burning of DTBP over KBD/D/1-DEC blends. Rajesh Kumar and Saravanan $(2015,2016)$ attempted pentanol as an additive to neat $\mathrm{BD}$ and achieved higher peak pressure than BD.

\subsection{Brake thermal efficiency}

BTE for KBD/D, diesel, KBD/D/1-DEC, KBD/D/DTBP is illustrated in Fig. 4. It is observed that the 0.7, 0.9 and 1.3\% increase in BTE were noticed for diesel than KBD/D/1-DEC, $\mathrm{KBD} / \mathrm{D} / \mathrm{DTBP}$ and KBD/D, respectively. BTE for diesel falls on the higher side. This is due to lesser fuel utilization and superior heating value (Sudalaimuthu et al. 2018; Vellaiyan 2019). However, upon adding 1-Pentadecanol and DTBP as an additive enhances the $\mathrm{BTE}$ for $\mathrm{KBD} / \mathrm{D}$. At $5 \mathrm{KW}$, BTE is improved by 0.2 (DTBP) and 0.4 (1-Pentadecanol) for KBD/D. Adding DTBP and 1-Pentadecanol lowers the overall viscosity by $6.1 \%$ and $4.7 \%$. This lower viscosity facilitates better evaporation, enhanced atomization, healthier spray pattern, homogenous mixture and higher BTE. Fuel with elevated $\mathrm{O}_{2}(\mathrm{KBD} / \mathrm{D}, \mathrm{KBD} / \mathrm{D} / 1-\mathrm{DEC}, \mathrm{KBD} / \mathrm{D} / \mathrm{DTBP})$

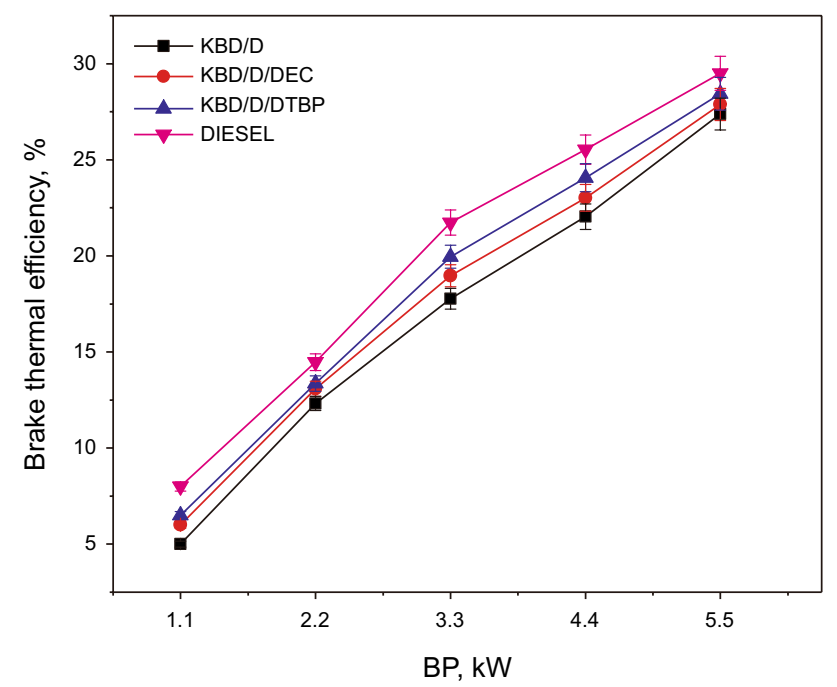

Fig. 4 BTE variations with BP combusts neatly at all phases and improves the fuel's chemical energy into work leading higher BTE. Jayapal et al. (2019) stated that the fuel with lower viscosity improves BTE for BD/alcohol blends. In another work, Yuvarajan and Venkata Ramanan (2016) stated that even 3\%-5\% reduction in viscosity of the fuel lowers the breakup distance and fuel penetration leading to a reduction in droplet size and result in rich mixing, improved atomization, enhanced vaporization, complete combustion and higher BTE. Similar inferences were observed in the different kinds of literature (Vellaiyan 2020a; Venu and Madhavan 2017; Sudalaimuthu et al. 2018; Saravanan et al. 2017; Rajesh Kumar et al. 2016) mentioning the small viscosity reduction can improve BTE.

\subsection{Brake specific fuel consumption}

BSFC for KBD/D, diesel, KBD/D/1-DEC and KBD/D/ DTBP is illustrated in Fig. 5. BSFC for diesel is lower than KBD/D/1-DEC, KBD/D/DTBP and KBD/D by 0.3 , 0.2 and $0.5 \mathrm{~kg} / \mathrm{kW}-\mathrm{hr}$, respectively. Lesser fuel utilization and higher CV lead to this trend. 0.2 and $0.3 \mathrm{~g} / \mathrm{kW}$-hr of $\mathrm{BSFC}$ is lowered for KBD/D/1-DEC and KBD/D/DTBP blends, respectively, than KBD/D blend at all BP. Admittance of 1-Pentadecanol and DTBP lowered the viscosity of KBD/D by $4.7 \%$ and $6.1 \%$. 1-Pentadecanol and DTBP lower cohesion between the fuel and disintegrate into finer droplets. There finer droplets of fuels are surrounded by air in all directions leading to complete combustion and lower BSFC. Further, $\mathrm{CV}$ of KBD/D/1-DEC and KBD/D/DTBP is improved by 150 and $300 \mathrm{KJ} / \mathrm{Kg}$ which lowers fuel utilization. Joy et al. (2019) found similar observation when fuelled with various BD/diesel/additive blends. Paul et al. (2017) and Perumal and Ilangkumaran (2017) at different studies mentioned that the fuel with lower viscosity achieves better

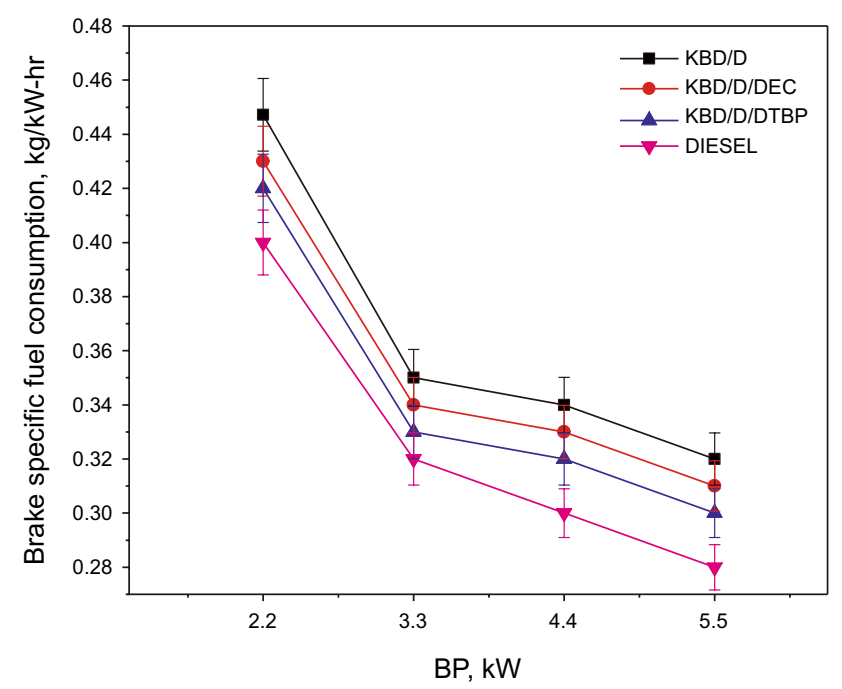

Fig. 5 BSFC variations with BP 
atomization which causes a homogeneous mixture of the fuel and reduces the internal friction between fuel molecules and quickly drives the small and large-chain hydrocarbons into smaller elements and makes fuel-bonded oxygen in the fuel to aggressively participate the combustion and lower BSFC. Similar inferences were observed in the different kinds of literature (Vellaiyan 2020b; Mahalingam 2018; Jayabal et al. 2019; Ganesan 2019; Devarajan et al. 2019a, b; Damodharan et al. 2017) mentioning the small viscosity reduction can lower BSFC.

\subsection{Oxides of nitrogen $\left(\mathrm{NO}_{\mathrm{x}}\right)$}

$\mathrm{NO}$ emissions for KBD/D, diesel, KBD/D/1-DEC and KBD/D/DTBP are illustrated in Fig. 6. NO emissions for diesel are least among test fuels. Diesel has lower in-built $\mathrm{O}_{2}$ and lower combustion time than other fuels (Bharathiraja et al. 2017). NO for KBD/D/1-DEC and KBD/D/DTBP is the maximum among all fuels. Appending 1-Pentadecanol and DTBP raises the NO for KBD/D. With $10 \%$ inclusion of DTBP, NO for KBD/D rises by 1.8 , whereas $10 \%$ inclusion of 1-Pentadecanol rises the NO by $3.1 \%$. Reduced combustion reaction period and increased temperature of combustion due to the catalytic activity of 1-Pentadecanol and DTBP increased the NO. Further DTBP and 1-Pentadecanol blends produce more $\mathrm{O}_{2}$ during combustion which agitates the NO formation. Different studies (Saravanan et al. 2017; Devarajan et al. 2020; Rathinam et al. 2019; Balan et al. 2018) proved that the $\mathrm{O}_{2}$-rich fuels always end up with higher NO emission.

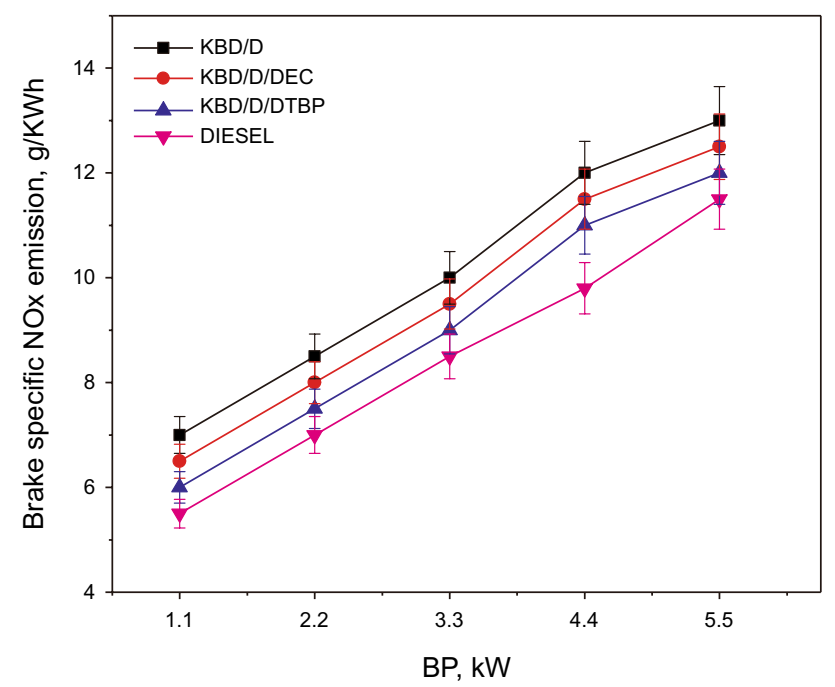

Fig. $6 \mathrm{NO}_{\mathrm{X}}$ variations with $\mathrm{BP}$

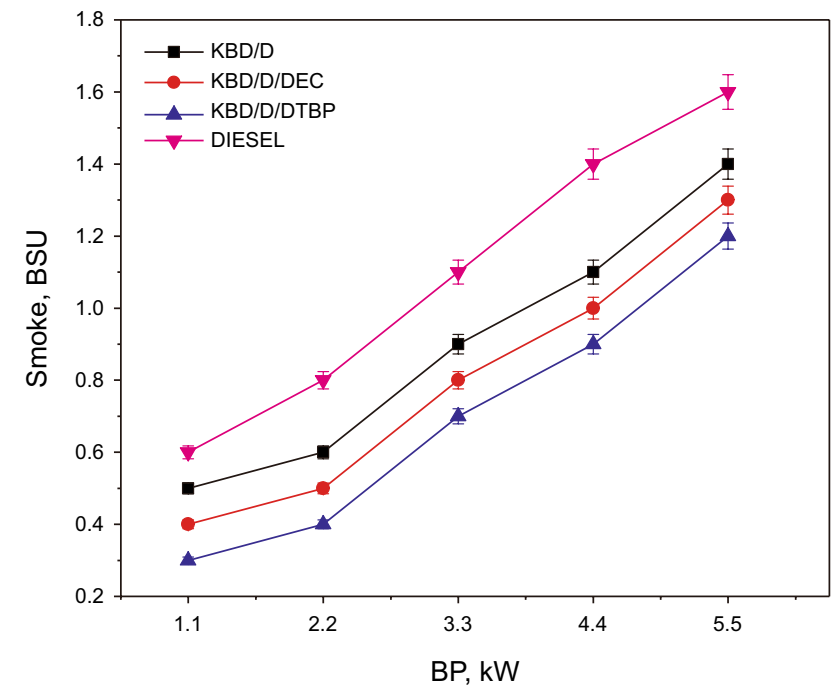

Fig. 7 Smoke variations with BP

\subsection{Smoke emissions}

Lesser $\mathrm{O}_{2}$ in fuel results in incomplete combustion and smoke formation. Smoke emissions for KBD/D, Diesel, KBD/D/1-DEC and KBD/D/DTBP are illustrated in Fig. 7. Smoke for modified fuels is relatively lesser than diesel at BP. Renewable fuels are rich in $\mathrm{O}_{2}$ availability. Oxygenrich combustion always ends up complete (Yuvarajan et al. 2016). Complete combustion leads to lower smoke emissions. Smoke further lowers by appending 1-Pentadecanol and DTBP to KBD/D. Smoke lowers by $3.2 \%$ and $4.9 \%$ by blending DTBP and 1-Pentadecanol at 10\% vol to KBD/D. Significant lessening of smoke emissions is correlated to less density, less viscosity, $\mathrm{O}_{2}$-rich combustion of modified fuels (KBD/D, KBD/D/1-DEC, KBD/D/DTBP). 1-Pentadecanol and DTBP blends in KBD/D mixture provide rich atomization, uniform combustion and lower smoke. Devarajan et al. (2020) used DTBP as a blend with papaya seed BD and lowered $4.2 \%$ of smoke emission.

\subsection{CO emissions}

Incomplete combustion propagates $\mathrm{CO}$ emissions. $\mathrm{CO}$ emissions for KBD/D, Diesel, KBD/D/1-DEC and KBD/D/ DTBP are illustrated in Fig. 8. The carbon oxidation reaction is improved while fuelled with renewable fuels. This improved reaction ends up with complete fuel burning and lowers $\mathrm{CO}$ as in the case of DTBP/1-Pentadecanol/KBD/D blends. Adding 10\% Volume of 1-Pentadecanol lowers $\mathrm{CO}$ emission of $\mathrm{KBD} / \mathrm{D}$ by $4.9 \%$, whereas $10 \%$ inclusion of DTBP lowers the CO emission by $7.6 \%$ at all BP for $\mathrm{KBD} / \mathrm{D}$. It is a known fact that the lesser viscous fuel 


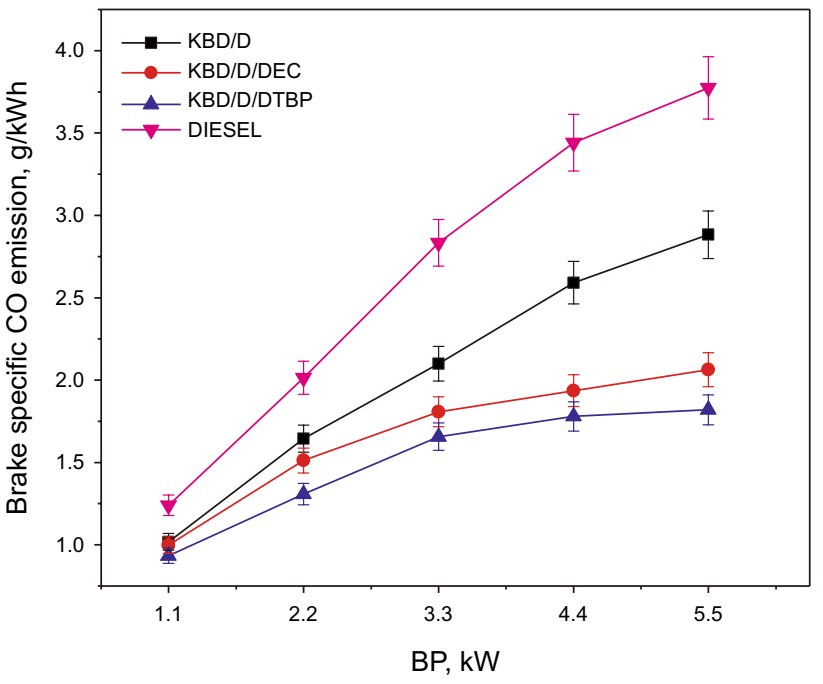

Fig. $8 \mathrm{CO}$ variations with $\mathrm{BP}$

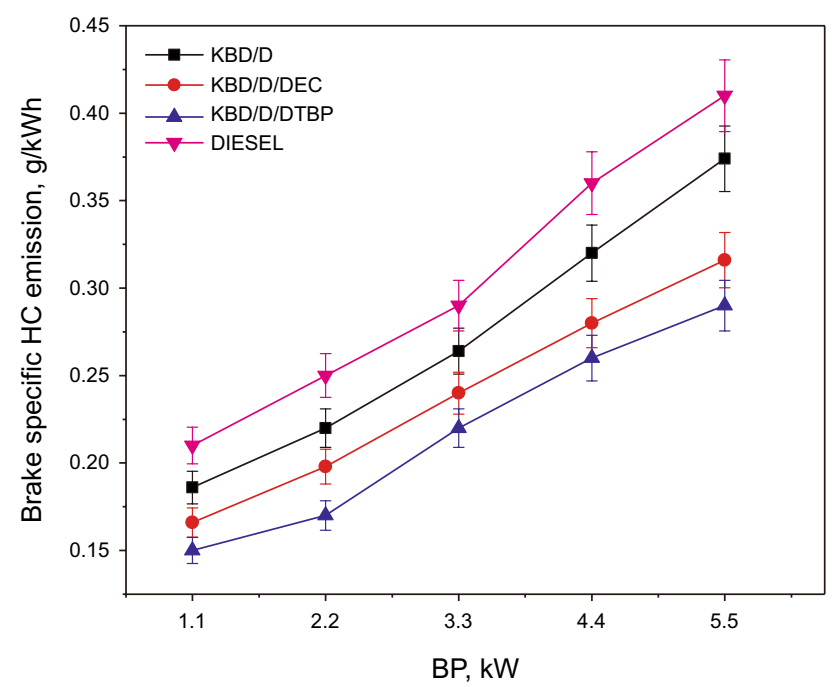

Fig. $9 \mathrm{HC}$ variations with $\mathrm{BP}$

atomizes and evaporates better. Fuel with better evaporation and atomization burns completely irrespective of its properties (Venu and Madhavan 2017). The fuel which burns cleanly results in lower CO emission. Devarajan et al. (2019a, b) and Devarajan (2018) employed different additives (DTBP and DMC) and lowered the $\mathrm{CO}$ emission than BD.

\subsection{HC emissions}

$\mathrm{HC}$ emissions for KBD/D, Diesel, KBD/D/1-DEC and $\mathrm{KBD} / \mathrm{D} / \mathrm{DTBP}$ are illustrated in Fig. 9. $\mathrm{HC}$ for $\mathrm{KBD} / \mathrm{D}$, diesel, $\mathrm{KBD} / \mathrm{D} / 1-\mathrm{DEC}$ and $\mathrm{KBD} / \mathrm{D} / \mathrm{DTBP}$ is $3.1 \%, 5.4 \%$ and $6.2 \%$ lower than diesel at all BP. $\mathrm{O}_{2}$ content and higher cetane index are the cause for this trend. Adding $10 \%$ of $\mathrm{n}$-1-Pentadecanol to KBD/D blends lowered the emission by $3.3 \%$, where $10 \%$ addition of DTBP lowered the same by $4.9 \%$. The significant reduction is due to cetane number (high), viscosity (less), $\mathrm{O}_{2}$ availability (high) of DTBP/ $\mathrm{KBD} / 1-\mathrm{DEC} / \mathrm{D}$ blends which ends up in better combustion and lower HC (Sudalaimuthu et al. 2018; Rathinam et al. 2019). Devarajan et al. (2019a, b) and Devarajan (2018) employed different additives (DTBP and DMC) and lowered the $\mathrm{HO}$ emission than $\mathrm{BD}$.

\section{Conclusion}

This study was intended to partially replace diesel fuel by employing non-edible biodiesel in diesel engine applications. Karanja biodiesel was selected as the source of biodiesel, and its ignition characteristics are further improved by blending it with two additives, 1-Pentadecanol and DTBP on $10 \%$ volume basis. Complete ignition studies were analyzed on the engine using diesel and modified fuels. Major findings from this work are as follows:

HRR and peak pressure were highest for diesel and least for KBD/D blends. However, blending the additives enhanced its HRR and peak pressure.

Improved physicochemical properties of 1-Pentadecanol and DTBP lowered BSFC and enhanced BTE for KBD/D blends and are comparable with diesel.

Higher NO emission was observed for KBD/D blends by blending additives. At all condition, $\mathrm{NO}$ emission for diesel remained the lowest.

Smoke, $\mathrm{HC}$ and $\mathrm{CO}$ emission lowered significantly by blending 1-Pentadecanol and DTBP to BD/diesel blends. Higher cetane index and lower viscosity lead to improved and complete combustion.

Open Access This article is licensed under a Creative Commons Attribution 4.0 International License, which permits use, sharing, adaptation, distribution and reproduction in any medium or format, as long as you give appropriate credit to the original author(s) and the source, provide a link to the Creative Commons licence, and indicate if changes were made. The images or other third party material in this article are included in the article's Creative Commons licence, unless indicated otherwise in a credit line to the material. If material is not included in the article's Creative Commons licence and your intended use is not permitted by statutory regulation or exceeds the permitted use, you will need to obtain permission directly from the copyright holder. To view a copy of this licence, visit http://creativecommons.org/licenses/by/4.0/.

\section{References}

Appavu P. Effect of injection timing on performance and emission characteristics of palm biodiesel and diesel blends. J Oil Palm Res. 2018;30:674-81. https://doi.org/10.21894/jopr.2018.0057. 
Balan KN, Yashvanth U, Booma Devi P, Arvind T, Nelson H, Devarajan Y. Investigation on emission characteristics of alcohol biodiesel blended diesel engine. Energy Sources Part A Recovery Util Environ Eff. 2018;41(15):1879-89. https://doi.org/10.1080/15567 036.2018.1549166.

Bharathiraja B, Jayamuthunagai J, Sudharsanaa T, Bharghavi A, Praveenkumar R, Chakravarthy M. Biobutanol—an impending biofuel for future: a review on upstream and downstream processing tecniques. Renew Sustain Energy Rev. 2017;68:788-807. https ://doi.org/10.1016/j.rser.2016.10.017.

Damodharan D, Sathiyagnanam AP, Rana D, Rajesh Kumar B, Saravanan S. Extraction and characterization of waste plastic oil (WPO) with the effect of $\mathrm{n}$-butanol addition on the performance and emissions of a DI diesel engine fueled with WPO/diesel blends. Energy Convers Manag. 2017;131:117-26. https://doi. org/10.1016/j.enconman.2016.10.076.

Devarajan Y. Experimental evaluation of combustion, emission and performance of research diesel engine fuelled di-methyl- carbonate and biodiesel blends. Atmos Pollut Res. 2018;10(3):795-801. https://doi.org/10.1016/j.apr.2018.12.007.

Devarajan Y, Beemkumar N, Ganesan S, Arunkumar T. An experimental study on the influence of an oxygenated additive in diesel engine fuelled with neat papaya seed biodiesel/diesel blends. Fuel. 2020;268:117254. https://doi.org/10.1016/j.fuel.2020.117254.

Devarajan Y, Choubey G, Mehar K. Ignition analysis on neat alcohols and biodiesel blends propelled research compression ignition engine. Energy Sources Part A Recovery Util Environ Eff. 2019a. https://doi.org/10.1080/15567036.2019.1618998.

Devarajan Y, Munuswamy D, Nagappan B, Subbiah G. Experimental assessment of performance and exhaust emission characteristics of a diesel engine fuelled with Punnai biodiesel/butanol fuel blends. Pet Sci. 2019b;16:1471-8. https://doi.org/10.1007/s12182-01900361-9.

Ganesan S. Effect of EGR \& nanoparticles on performance and emission characteristics of a diesel engine fuelled with palm biodiesel and diesel blends. J Oil Palm Res. 2019;31:130-7. https://doi. org/10.21894/jopr.2018.0065.

Ganesan S, Sivasubramanian R, Sajin JB, Ganesan S, Yuvarajan D. Performance and emission study on the effect of oxygenated additive in neat biodiesel fueled diesel engine. Energy Sources Part A Recovery Util Environ Eff. 2018;41(6):2017-27. https://doi. org/10.1080/15567036.2018.1549148.

Jayabal R, Thangavelu L, Velu C. Experimental investigation on the effect of ignition enhancers in the blends of sapota biodiesel/diesel blends on a CRDi engine. Energy Fuels. 2019. https://doi. org/10.1021/acs.energyfuels.9b02521.

Joy N, Yuvarajan D, Beemkumar N. Performance evaluation and emission characteristics of biodiesel-ignition enhancer blends propelled in a research diesel engine. Int $\mathrm{J}$ Green Energy. 2019;16(4):277-83. https://doi.org/10.1080/15435 075.2018.1561455.

Kavitha KR, Beemkumar N, Rajasekar R. Experimental investigation of diesel engine performance fuelled with the blends of Jatropha curcas, ethanol, and diesel. Environ Sci Pollut Res. 2019;26(9):8633-9. https://doi.org/10.1007/s11356-019-04288-x.

Mahalingam A. Investigation on the emission reduction technique in acetone-biodiesel aspirated diesel engine. J Oil Palm Res. 2018;30:345-9. https://doi.org/10.21894/jopr.2018.0020.

Paul A, Panua R, Debroy D. An experimental study of combustion, performance, exergy and emission characteristics of a CI engine fueled by Diesel-ethanol-biodiesel blends. Energy. 2017;141:839 52. https://doi.org/10.1016/j.energy.2017.09.137.

Perumal V, Ilangkumaran M. Experimental analysis of engine performance, combustion and emission using pongamia biodiesel as fuel in CI engine. Energy. 2017;129:228-36. https://doi.org/10.1016/j. energy.2017.04.120.

Radhakrishnan S. Emissions analysis on diesel engine fueled with palm oil biodiesel and pentanol blends. J Oil Palm Res. 2017;29:380-6. https://doi.org/10.21894/jopr.2017.2903.11.

Radhakrishnan S, Munuswamy DB, Devarajan Y, Arunkumar T, Mahalingam A. Effect of nanoparticle on emission and performance characteristics of a diesel engine fueled with cashew nut shell biodiesel. Energy Sources Part A Recovery Util Environ Eff. 2018. https://doi.org/10.1080/15567036.2018.1502848.

Rajesh Kumar B, Saravanan S. Effect of exhaust gas recirculation (EGR) on performance and emissions of a constant speed DI diesel engine fueled with pentanol/diesel blends. Fuel. 2015;160:217-26. https://doi.org/10.1016/j.fuel.2015.07.089.

Rajesh Kumar B, Saravanan S. Effects of iso-butanol/diesel and n-pentanol/diesel blends on performance and emissions of a DI diesel engine under premixed LTC (low temperature combustion) mode. Fuel. 2016;170:49-59. https://doi.org/10.1016/j.fuel.2015.12.029.

Rajesh Kumar B, Saravanan S, Rana D, Anish V, Nagendran A. Effect of a sustainable biofuel - n-octanol - on the combustion, performance and emissions of a DI diesel engine under naturally aspirated and exhaust gas recirculation (EGR) modes. Energy Convers Manag. 2016;118:275-86. https://doi.org/10.1016/j. enconman.2016.04.001.

Rathinam S, Balan K, Subbiah G, Sajin J, Devarajan Y. Emission study of a diesel engine fueled with higher alcohol-biodiesel blended fuels. Int J Green Energy. 2019;16(9):667-73. https:// doi.org/10.1080/15435075.2019.1617001.

Saravanan S, Rajesh Kumar B, Varadharajan A, Rana D, Sethuramasamyraja B, Lakshmi Narayanarao G. Optimization of DI diesel engine parameters fueled with iso-butanol/diesel blendsresponse surface methodology approach. Fuel. 2017;203:658-70. https://doi.org/10.1016/j.fuel.2017.04.083.

Siva R, Munuswamy DB, Devarajan Y. Emission and performance study emulsified orange peel oil biodiesel in an aspirated research engine. Pet Sci. 2018. https://doi.org/10.1007/s12182-018-0288-0.

Sudalaimuthu G, Rathinam S, Munuswamy DB, Thirugnanasambandam A, Devarajan Y. Testing and evaluation of performance and emissions characteristics of water- biodiesel aspirated research engine. J Test Eval. 2018;48(5):20180306. https://doi. org/10.1520/jte20180306.

Vellaiyan S. Enhancement in combustion, performance, and emission characteristics of a diesel engine fueled with diesel, biodiesel, and its blends by using nanoadditive. Environ Sci Pollut Res. 2019;26(10):269561e-269573.

Vellaiyan S. Effect of cerium oxide nanoadditive on the working characteristics of water emulsified biodiesel fueled diesel engine; an experimental study. Therm Sci. 2020a;24(1A):231-41.

Vellaiyan S. Enhancement in combustion, performance, and emission characteristics of a biodiesel-fueled diesel engine by using water emulsion and nanoadditive. Renew Energy. 2020b;145:2108-20.

Venu H, Madhavan V. Influence of diethyl ether (DEE) addition in ethanol-biodiesel-diesel (EBD) and methanol-biodiesel-diesel (MBD) blends in a diesel engine. Fuel. 2017;189:377-90. https ://doi.org/10.1016/j.fuel.2016.10.101.

Yuvarajan D, Venkata Ramanan M, Christopher Selvam D. Performance analysis on mustard oil methyl ester as a potential alternative fuel. Indian J Sci Technol. 2016. https://doi.org/10.17485/ ijst/2016/v9i37/101982.

Yuvarajan D, Venkata Ramanan M. Experimental analysis on neat mustard oil methyl ester subjected to ultrasonication and microwave irradiation in four stroke single cylinder Diesel engine. J Mech Sci Technol. 2016;30(1):437-46. https://doi.org/10.1007/s1220 6-015-1248-x. 